\title{
Elective Microlaryngeal Surgery
}

\section{Omar Seguras Llanes}

Specialist of $1^{\text {st }}$ and $2^{\text {nd }}$ grades in Anesthesiology and Reanimation. Master in Medical Urgencies. Auxiliary Professor. Diplomat in Intensive Cares. Central Military Hospital "Dr. Carlos J Finlay”. Havana. Cuba.

* Corresponding author: Omar Seguras Llanes, Specialist of 1st and 2nd grades in Anesthesiology and Reanimation. Master in Medical Urgencies. Auxiliary Professor. Diplomat in Intensive Cares. Central Military Hospital “Dr. Carlos J Finlay”. Havana. Cuba. Email: omarsegura@infomed.sld.cu

Received date: December 14, 2019; Accepted date: January 02, 2020; published date: January 09, 2020

Citation: Omar Seguras Llanes (2020) Safety and Effectiveness of Jet Ventilation with Conventional Ventilatory Frequencies for Elective Microlaryngeal Surgery. J Clinical Research and Reports, 2(1); DOI:10.31579/jcrr.2020/009

Copyright: () 2020 Omar Seguras Llanes. This is an open access article distributed under the Creative Commons Attribution License, which permits unrestricted use, distribution, and reproduction in any medium, provided the original work is properly cited.

\begin{abstract}
\section{Introduction}

Ventilate patients during microlaryngeal surgery confronts several problems. Jet ventilation with conventional ventilatory frequencies allows the use of small diameter endotracheal catheters to provide adequate oxygen volumes and better operating conditions than the traditional method.
\end{abstract}

\section{Objective}

Evaluate the safety and effectiveness of jet ventilation with conventional ventilatory frequencies for elective microlaryngeal surgery.

\section{Methods}

A comparative, single-blind, randomized and parallel study was performed. It was used a prototype of jet ventilation device (with an exceptional use permit in humans conferred by the Center for the State Control of Medication, Dispositive and Medical Equipment) in a study group of 45 patients (group E) and compared with a control group (group C) of 15 patients using the traditional ventilation method.

\section{Results}

Oxygenation was higher in group E. Group C eventually required extubation, transitory apnea and reintubation, which impacted against the anatomophysiological integrity of patients, the operative field and teaching. A greater hemodynamic stability was evident among the subjects of group E. The intrapulmonary pressures produced by jet ventilation did not cause obvious injuries or clinical repercussions.

\section{Conclusions}

Applying jet ventilation with conventional ventilatory frequencies was safe and effective. For the first time, experiences of using a jet ventilation method in the country were obtained. The group in which traditional ventilation method was applied suffered more frequent and dangerous complications. It is necessary to assimilate jet ventilation's technologies to raise the quality of medical attention in times of peace, war or disasters, in elective or emerging contexts as the challenge of a difficult airway.

Keywords: jet ventilation; tracheal intubation; microlaryngeal surgery; difficult airway; cricothyroidotomy

\section{Introduction}

In 1967, Sander introduced the high-frequency jet (HFJV) [1] to facilitate ventilation during bronchoscopies, with pressures of 15 - 50 psi, tidal volumes of $2-5 \mathrm{ml} \mathrm{kg}^{-1}$ and a respiratory rate (RR) of $100-200 \mathrm{bpm}$. The $\mathrm{I} / \mathrm{E}$ ratio was controlled by the operator empirically. The exhalation depends on the toracopulmonary elasticity.

High-frequency positive pressure ventilation (HFPPV) was introduced by Oberg and Sjostrand (1969) to reduce variations in chest volume and the reflections of carotid sinus, generated during conventional ventilation.

Auctores Publishing - Volume 2(1)-009 www.auctoresonline.org
Likewise, the exhalation is passive and therefore, intrapulmonary gas entrapment can occur.

In 1972, Lunkenheimer and others introduced high frequency oscillation (HFO) with the use of pumps or diaphragms; unlike HFPPV and HFJV, in HFO both exhalation and inspiration are actively performed.

Since then these ventilation techniques have been developed in conjunction with worldwide scientific-technical advances $[2,10]$. Multiple mechanisms can contribute to the supply of gas during jet ventilation, as such as: bulk flow; longitudinal dispersion (Taylor); pendulum; asymmetric laminar speed; cardiogenic mixture; and molecular diffusion. 
An alternative since the 1990s was Superimposed high-frequency jet ventilation (SHFJV), developed specifically for laryngotracheal surgery, and using two jet flows with two simultaneous frequencies: HFJV and jet ventilation with conventional ventilatory frequencies (JVCVF) [10].

During laryngeal microsurgery by direct laryngoscopy the surgical field coincides with the upper airway access site, which the anesthesiologist must also invade to preserve respiratory variables.

The technology traditionally used (conventional ventilation) faces serious problems, because the endotracheal tubes interfere with the surgeon's access to the surgical field, and lead to trauma to the tracheobronchial wall by sometimes being necessary to remove and reposition in order to facilitate the surgical procedure, in addition to the risks to which the patient is exposed during these periods of apnea. In this situation, jet oxygen can be used, as jet flow at high pressure and conventional frequencies, through small diameter catheters (suction probes, intravenous cannulas) to introduce an amount of oxygen into the trachea equivalent to that can be provided by means of a larger diameter tube, which facilitates much higher operating conditions in terms of surgical field, accessibility and surgical maneuvering, without major risks to the patient $[68,11,12]$.

Similarly, modern emergency algorithms such as head trauma and/or severe cervical injuries, and patients with difficult airways, recommend the use of trans-cricothyroid jet devices, which allow oxygenation and ventilation until a definitive airway is established, which preserves the patient's life and decreases the high morbidity of such emergencies [13, 15].

Because the above, is the objective of this study to evaluate the safety and effectiveness of JVCVF for elective laryngeal microsurgery, and in order to facilitate the results` interpretation it was compared with the conventional method of ventilation, traditionally applied for this kind of surgical proceeding.

\section{Methods}

A comparative study was conducted, simply blind, randomized and parallel at the Central Military Hospital "Dr. Carlos J. Finlay" and for the first time in the country. The universe was made up of adult patients of any age, sex and body weight, whose surgical procedures will involve general anesthesia for diagnostic-therapeutic interventions using direct laryngoscopy.

The sample consisted of the patients who agreed to participate in the experiment, according to the pre-established inclusion and exclusion

Resuscitation in the two groups was based on the consequent suspension of the hypnotic and neuromuscular blocker. In group E, a JVCVF regimen was switched on to spontaneous ventilation recovery. Then there was proceeded to extubate. Oropharyngeal secretions were removed by suction, and the ventilation probe was also used to remove secretions during its removal from the trachea.

In group $\mathrm{C}$, intubation was performed by direct laryngoscopy with Macintosh curved blade and $6-7.5$ gauge endotracheal probes. To direct the probe towards the glottis, a metal guide was used when necessary. Tracheal intubation was proven by capnography. The chest was inspected and auscultated for proper bipulmonary ventilation. The endotracheal tube was criteria. These patients were randomly grouped into a study group (group E) of 45 patients under JVCVF and compared with a control group (group C) of 15 patients ventilated using the traditional method. Work was done with a prototype jet ventilation device [exceptional authorization No: 004/17, to conduct a pilot study in humans, dated August 2, 2017, conferred by the Center for the State Control of Medication, Dispositive and Medical Equipment (CECMED)] (see Annex).

Preoperative medication was applied 30 - $60 \mathrm{~min}$ prior to induction: hydrocortisone (100 $\mathrm{mg} \mathrm{IV}$ ) and atropine $(0.5 \mathrm{mg} \mathrm{IV})$. In the operating room each patient was monitored with Life Scope 11: peripheral saturation of oxygen ( $\mathrm{SpO} 2)$; end tidal carbon dioxide (EtCO2); electrocardiography $(\mathrm{EKG})$ in D-II; not invasive blood pressure (NIBP); heart rate (HR); and RR.

The anesthetic induction via IV was established as follows: atracurium (5 $\mathrm{mg})$; fentanyl $(150 \mu \mathrm{g})$; lidocaine $(100 \mathrm{mg})$; propofol $\left(1-2 \mathrm{mg} \mathrm{kg}^{-1}\right.$.) and succinylcholine $\left(1-3 \mathrm{mg} \mathrm{kg}^{-1}\right)$.

In group E, intubation was performed by direct laryngoscopy with Macintosh curved blade for transglotic, endotracheal and supracarinal placement of a blind-end suction probe with double distal perforation (common in operating theatres), which required the use of a Magill clip in some cases. The epigastrium was inspected and auscultated previously to verify the suction probe position by capnometry. The chest was then inspected and auscultated to verify chest expansionability and symmetrical vesicular murmur in both lungs. The suction probe (became ventilation probe) was then secured with duct tape as it exited the left lip corner and connected to the jet ventilation device. The otorhinolaryngologist (ORL) surgeons were then given way.

In this group the jet ventilation was manually controlled. Its monitoring was performed by a lateral extraction capnometry method with values between $16-29 \mathrm{Hg}$, a RR between 8 - $20 \mathrm{bpm}$, clinically controlled peak airway pressures and a $100 \%$ of FiO2. Whenever possible during the surgical act, the analgesic basis of induction was used in both groups; if not, were used fentanyl via IV, $1-3 \mu \mathrm{g} \mathrm{kg}^{-1}$ when needed. The vital signs of patients were jealously observed with the aim of maintaining a deep state of hypnosis, administering propofol's doses of $0.5-1 \mathrm{mg} \mathrm{kg}^{-1}$ via IV in the presence of signs of anesthetic superficiality [increase of $20 \%$ or more of systolic blood pressure (SBP); increase of $20 \%$ or more of HR; ventricular extrasystoles; sweating; pyloerection]. Muscle relaxation was equally clinically followed up; IV doses of succinylcholine of $0.5-1 \mathrm{mg} \mathrm{kg}^{-1}$ were administered in the face of superficiality evidence.

secured with duct tape as it left a lip corner, was connected to the mechanical ventilator and then was gave way to ORL surgeons. This group was maintained with conventional ventilation mechanically controlled by Acoma ventilator machine and monitored by in-line capnography, with values between $30-60 \mathrm{~mm} \mathrm{Hg}$, RR between $8-20 \mathrm{bpm}$, peak airway pressures between $10-40 \mathrm{~cm} \mathrm{H} 2 \mathrm{O}$ and a FiO2 of $100 \%$. During group $\mathrm{C}$ resuscitation, the trachea was transferred to manual assisted ventilation and then extubated, after aspiration of secretions.

Patients from both groups were transferred to the post-anesthetic care unit (PACU) and monitored until their hospital discharge.

Auctores Publishing - Volume 2(1)-009 www.auctoresonline.org

Page 2 of 8 


\section{Results}

The characterization of groups according to general variables was similar in the average values of age and body weight, which facilitated the interpretation of the results.

Statistically significant difference $(\mathrm{p}<0.05)$ existed between total anesthetic times (group E: $22.4 \mathrm{~min}$; group C: $32.8 \mathrm{~min}$ ), which corresponded to the notable difference $(p<0.05)$ in resuscitation times between the two groups (group E: $6.2 \mathrm{~min}$; group C: $16.1 \mathrm{~min}$ ), probably due to increased consumption of anesthetic drugs during the intraoperative period for the type of conventional ventilation proceeding (Tables 1 and 2 ).

\begin{tabular}{|c|c|c|c|}
\hline & & & \\
Time (min) & Group E & Group C & t-Studentdistribution(p \\
\hline Surgical time & 10,5 & 14,9 & $0,023 *$ \\
\hline Induction time & 5,1 & 5,3 & 0,484 \\
\hline Maintenance time & 12,9 & 15,9 & 0,113 \\
\hline Reanimation time & 7,4 & 14,8 & $0,000 *$ \\
\hline
\end{tabular}

Table 1: Time consumption during the anesthetic-surgical proceedings.

Source: Data recollection model ( $*$ Statistic significant when results in $p$ values $<0,05$ )

\begin{tabular}{|c|c|c|c|}
\hline Drugs & Group E & Group C & $\begin{array}{c}\text { t-Student } \\
\text { distribution } \\
\text { (p) }\end{array}$ \\
\hline Propofol $\left(\mathrm{mg} \mathrm{kg}^{-1}\right)$ & 2,99 & 3,36 & $\mathrm{p}=0,121$ \\
\hline Fentanyl $\left(\mu \mathrm{gg}^{-1}\right)$ & 2,28 & 2,87 & $\mathrm{p}=0,022 *$ \\
\hline Succinylcholine $\left(\mathrm{mg} \mathrm{kg}^{-1}\right)$ & 4,3 & 5,79 & $\mathrm{p}=0,000 *$ \\
\hline Atropine $\left(\mathrm{mg} \mathrm{kg}^{-1}\right)$ & 0,0 & 0,013 & $\mathrm{p}=0,035 *$ \\
\hline Propranolol $\left(\mathrm{mg} \mathrm{kg}^{-1}\right)$ & 0,015 & 0,015 & $\mathrm{p}=0,102$ \\
\hline Lidocaine $\left(\mathrm{mg} \mathrm{kg}^{-1}\right)$ & 0,0 & 1,51 & $\mathrm{p}=0,115$ \\
\hline
\end{tabular}

Table 2: Anesthetic drugs consumption.

( $*$ Statistic significant when results in p values $<0,05$ )

No transoperative or postoperative signs of intra-lung hyperpressure, airway injury, or hemodynamic instability effects induced by the method applied in patients with JVCVF were shown. However, intrapulmonary pressures that collided with the maximum pressure limit (P1) set in the Acoma mechanical ventilator ( $\mathrm{P} 1$ of $40 \mathrm{~cm} \mathrm{H} 2 \mathrm{O}$ ) during the established conventional ventilation were detected, in some group $\mathrm{C}$ subjects; equally in this group the tendency to greater hemodynamic instability was manifested.
Graphic 1 shows the transoperative trend of EtCO2. In group E, EtCO2

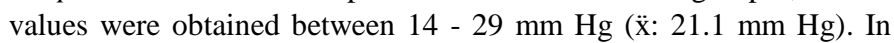

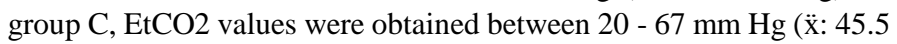
$\mathrm{mm} \mathrm{Hg}$ ), and in this group the incidence of transient episodes of hypoventilation, accompanied by sweating, high blood pressure and brady or tachyarrhythmia's requiring medical treatment, was significant. 


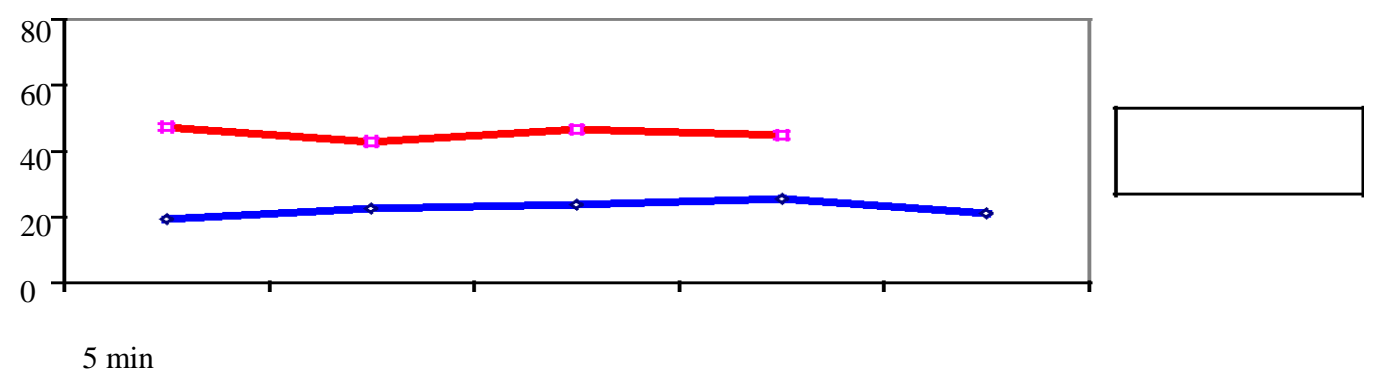

Graphic 1: EtCO2 trend $(\mathrm{mm} \mathrm{Hg})$

The hemodynamic variables measured in this study were analyzed by means of their limit and average values (group E: SBP between 90 175 mm Hg, $\ddot{x}: 126.1 \mathrm{~mm} \mathrm{Hg}$; HR between 49 - 120 beat min $^{-1}$, $\ddot{x}: 84.3$ beat $\mathrm{min}^{-1}$. And group C: SBP between $87-197 \mathrm{~mm} \mathrm{Hg}$, $: 133.8 \mathrm{~mm}$ $\mathrm{Hg}$; HR between $40-138$ beat $\min ^{-1}$, $\ddot{\mathrm{x}}: 89.3$ beat $\mathrm{min}^{-1}$ ). Greater

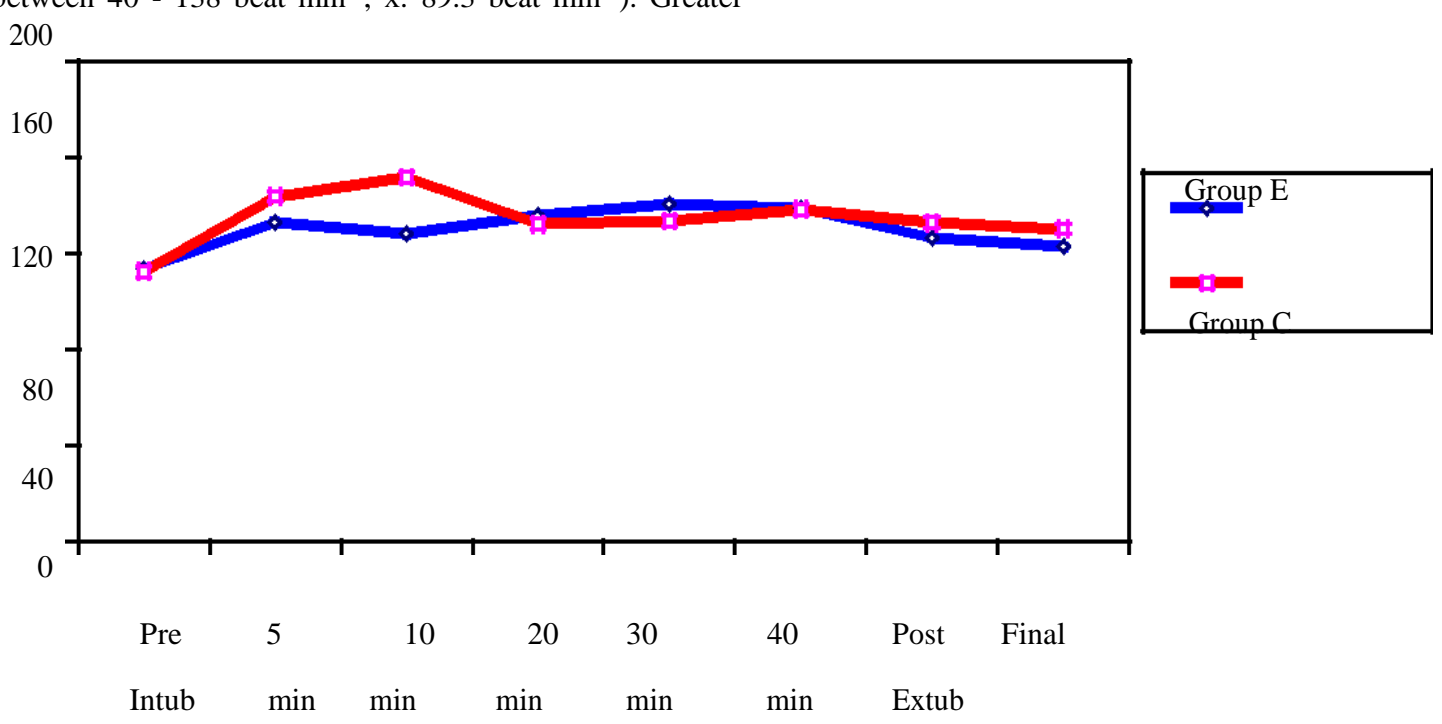

Graphic 2: SBP trend $(\mathrm{mm} \mathrm{Hg})$

In Graphic 3, SpO2 shows better results among jet-ventilated subjects at conventional ventilatory frequencies (group E: SpO2 between 88 - 100 $\%$, х̈: $98.5 \%$; group C: $\mathrm{SpO} 2$ between $68-100 \%$,

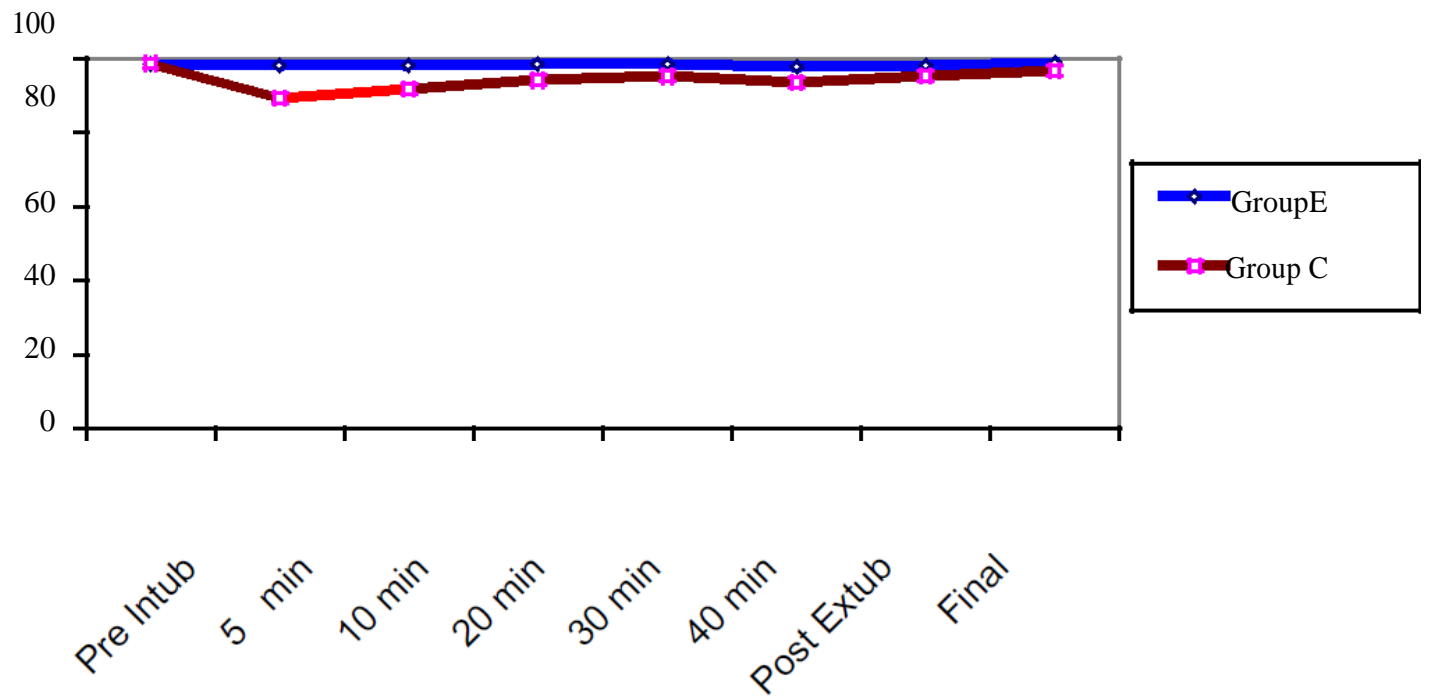


Graphic 3: Oxigenation trend (\%)

At PACU, the four variables analyzed in group $\mathrm{E}$ were best performed, relative to group $\mathrm{C}$ (Table 3).

\begin{tabular}{|c|c|c|c|}
\hline HR (beats min $\left.^{-1}\right)$ & Average & SpO $_{2}(\%)$ & Average \\
\hline Group E & $\begin{array}{c}50-98 \\
(\ddot{X}: 79,2)\end{array}$ & Group E & $\begin{array}{r}90-100 \\
(\ddot{X}: 98,4)\end{array}$ \\
\hline Group C & $\begin{array}{c}48-122 \\
(\ddot{X}: 83,4)\end{array}$ & Group C & $\begin{array}{l}86-100 \\
(\ddot{X}: 96,2)\end{array}$ \\
\hline SBP (mm Hg) & Average & Stay (min) & Average \\
\hline Group E & $\begin{array}{c}89-170 \\
(\ddot{X}: 123,5)\end{array}$ & Group E & $\begin{array}{c}60-75 \\
(\ddot{X}: 65,0)\end{array}$ \\
\hline Group C & $\begin{array}{c}91-178 \\
(\ddot{X}: 129,4)\end{array}$ & Group C & $\begin{array}{c}60-115 \\
(\ddot{X}: 80,0)\end{array}$ \\
\hline
\end{tabular}

Source: Data recollection model

The assessment of immediate postoperative pain according to the personal criteria of the patients (Likert Scale) showed better results among patients in group E, not statistically significant (group E: $\ddot{x}: 4.91$ points; group C: $\ddot{x}: 4.33$ points).

Complications (Table 4) are shown in percent of each groups and reveal the incidence of fewer complications, as well as reduced hazard, among patients in group $\mathrm{E}$.

\begin{tabular}{|c|c|c|c|c|}
\hline \multirow[b]{2}{*}{ Complications } & \multicolumn{2}{|c|}{ Group E } & \multicolumn{2}{|c|}{ Group C } \\
\hline & TOP & POP & TOP & POP \\
\hline & $\%$ & $\%$ & $\%$ & $\%$ \\
\hline Bradyarrhythmia & 0 & $\overline{0}$ & 6,6 & 6,6 \\
\hline Tachyarrhythmia & 4,4 & 0 & 26,6 & 13,3 \\
\hline Severe HBP $(\mathrm{SBP} \geq 180)$ & 2,2 & 0 & 6,6 & 6,6 \\
\hline Nausea-Vomiting & 0 & 0 & 0 & 6,6 \\
\hline Muscular pain & 0 & 2,2 & 0 & 6,6 \\
\hline Dysphagia & 0 & 4,4 & 0 & 6,6 \\
\hline Shivering & 0 & 2,2 & 0 & 6,6 \\
\hline Persistent cough & 0 & 2,2 & 0 & 13,3 \\
\hline Dry mouth & 0 & 2,2 & 0 & 13,3 \\
\hline
\end{tabular}

Source: Data recollection model

Table 4: Trans and postoperatory complications. 
Male dominance was observed in both groups ( $60 \%$ or more), reflecting a higher incidence of premalignant and malignant lesions at the laryngeal level in this genus, as cited in the National Yearbook of Health Statistics of Cuba 2010 [16]. There is an obvious prevalence of the male sex in the suffering of such lesions, having the highest ratio of $\mathrm{M} / \mathrm{F}$ sex rates among all tumors, which is 7.5. Its incidence is almost absolutely from the age of 40 [16].

Intrapulmonary pressures produced when applying JVCVF were assessed clinically, minute by minute according to chest expansionability, free gas leakage through an expedited upper airway and patient hemodynamic stability. According to Atkins and others, clinical evidence of stable hemodynamic is an element in favor of adequate intrapulmonary pressures. One way to measure airway pressures is by monitoring hemodynamic changes, knowing that average airway pressure (media Paw) is the average of all pressures that circulate the lungs and chest during a respiratory cycle, and correlates with alveolar volume and arterial oxygenation, directly affects venous return, cardiac output and is a factor in the hemodynamic effects of ventilation.

Some authors who used different jet ventilation modalities agree to report quantitatively lower mean EtCO2 values than when conventional ventilation methods are used as a result of dilution of gases breathed in an open circuit to the atmosphere, where in turn large volumes of $\mathrm{O} 2$ and excess air are eliminated from jet flows $[1,7,11,15]$. However, according to Bourgain and others, these numerically lower values did not qualitatively affect the monitoring ventilation, when they correlated it with the values of $\mathrm{PaCO} 2$ [7].

Misiolek and others [17] obtained similar cardiovascular function parameters (HR, SBP, mean blood pressure, cardiac indices, systemic vascular resistance), comparing ventilation to a single lung with HFJV for thoracic surgery. Their findings are coincidental and reaffirm the hemodynamic results obtained by applying JVCVF in this study.

In conventional proceedings it became necessary to extubate, maintain in apnea and reintubate, even on several occasions the same patient, with greater interference on the operating field, greater stress of the surgical team and less ease for teaching.

Probably this also influenced the statistically significant decrease in oxygenation in group C. Several authors agree on reports of better results in the oxygenation variables analyzed, when comparing different techniques of jet ventilation with other ventilatory modes $[3-5,10,17]$.

The best results of variables in post-anesthetic care, postoperative pain assessment and the lower incidence and severity of complications among patients in group $\mathrm{E}$ are comparable to the results of monographs published by other authors $[3,5,9,13]$.

In this experience, during the proceedings of microsurgery of larynx the JVCVF was safe, effective and surpassed conventional ventilation in several topics.

It is concluded that the use of jet ventilation with conventional ventilatory frequencies was safe and effective. For the first time, experiences of using a jet ventilation method are obtained in the country. The group in which conventional ventilation was applied suffered more frequent and dangerous complications. Jet ventilation technologies need to be assimilated to raise the quality of health care in times of peace, war or disaster, in elective or emerging contexts as the challenge of a difficult or impossible airway.

\section{References}

1. Glenski JA, MacKenzie RA, Maragos NE, Southora PA (1985) Assessing tidal volume and detecting hyperinflation during venturi jet ventilation for microlaryngeal surgery. Anesthesiology. 63:554-5.

2. Atkins JH, Mirza N, Mandel JE (2009) Case report: respiratory inductance plethysmography as a monitor of ventilation during laser ablation and balloon dilatation of subglottic tracheal stenosis. ORL J. 71(5):289-91.

3. Benumof JL (1991) Management of the difficult adult airway. Anesthesiology. (75):1087-110.

4. Atkins JH, Mandel JE, Weinstein GS, Mirza N (2010) A pilot study of respiratory inductance plethysmography as a safe, noninvasive detector of jet ventilation under general anesthesia. Anesth Analg. 111(5):1168-75.

5. Nicelli E, Gemma M, De Vitis A, Foti G, Beretta L (2010) Feasibility of standard mechanical ventilation with low $\mathrm{FiO} 2$ and small endotracheal tubes during laser microlaryngeal surgery. Head Neck. 32(2):204-9.

6. Abad HL, Ajalloueyan M, Jalali AR (2007) Impact of body mass index (BMI) on ventilation during low-frequency jet ventilation. Otolaryngol Head Neck Surg. 136(3):477-80.

7. Bourgain JL, McGee K, Cosset MF, Bromley L, Meistelman C (1990) Carbon dioxide monitoring during high frequency jet ventilation for direct laryngoscopy. Br J Anaesth. 64(3):327-30.

8. Ahmed-Nusrath A, Nusrath MA, Bryant D (2010) Precautions required for needle thyroid-cricotomy. Br J Oral Maxillofac Surg. 48(5):396-7.

9. Williams A, Patel A, Ferguson C (2008) High frequency jet ventilation through the laryngeal mask airway in a critically obstructed airway. Anaesthesia. 63(12):1369-71.

10. Bourgain JL, Chollet M, Fischler M, Gueret G, Mayne A (2010) Guide for the use of jet-ventilation during ENT and oral surgery. Ann Fr Anesth Reanim. 29(10):720-7.

11. Hunsaker DH (1994) Anesthesia for microlaryngeal surgery: the case for subglottic jet ventilation. Laryngoscope. 104(65):1-30.

12. Biro P (2010) Jet ventilation for surgical interventions in the upper airway. Anesthesiol Clin. 28(3):397-409.

13. Gilbey P, Kukuev Y, Samet A, Talmon Y, Ivry S (2009) The quality of the surgical field during functional endoscopic sinus surgery -the effect of the mode of ventilation- a prospectiveized, double-blind study. Laryngoscope. 119(12):2449-2453.

14. Buise $M$, van Bommel J, van Genderen $M$, Tilanus $H$, van Zundert A et al (2009) Two-lung high-frequency jet ventilation as an alternative ventilation technique during transthoracic esophagectomy. J Cardiothorac Vasc Anesth. 23(4):509-12.

15. Smirnov AE, Klochikhin AL (2010) Maintenance of respiratory function during direct laryngoscopy in patients with laryngeal neoplasms. Vestn Otorinolaringol. (1):33-7.

16. Statistical Yearbook of Health (2010) of Cuba. MINSAP. National Directorate of Medical Records and Health Statistics. Havana; 2011. p. 78-81.

17. Misiolek H, Knapik P, Swanevelder J, Wyatt R, Misiolek M (2008) Comparison of double-lung jet ventilation and one-lung ventilation for thoracotomy. Eur J Anaesthesiol. 25(1):15-21. 